\title{
The application of Hippocratic principles to pediatric radiology
}

\author{
Bruce R. Parker
}

Received: 1 December 2013 / Accepted: 17 January 2014 / Published online: 26 February 2014

(C) Springer-Verlag Berlin Heidelberg 2014

Hippocrates of Kos, universally acknowledged as the "father of western medicine," and his writings have largely become the province of scholars of classical Greece and the history of medicine. The millennia-old Hippocratic Oath is often replaced in medical schools by more contemporary substitutes or done away with. One can reasonably ask if Hippocrates has any relevance to medicine in the age of molecular imaging, gene-based therapy and other remarkable advances in the modern medical world. That a widely known and admired physician named Hippocrates lived in the $5^{\text {th }}$ Century, B.C., is assured by mention of him in the writings of Plato (Protagoras 311B, Phaedrus 270 C-E) [1] and Aristotle (Politics 1326a) [2], among others. He was a member of the family of Asklepiades [3] and, as legend has it, was in the $16^{\text {th }}$ lineal generation of descent from the classical physician-god, Asklepius. He was taught medicine by his father and grandfather in the classical tradition of medical apprenticeship and he became the leading medical educator of his day, legendarily teaching dozens of students in the shade of a great plane tree on Kos until he moved to mainland Greece in middle age.

Hippocrates' great contribution to medicine, however, was bringing the field out of the supernatural world into the natural one. He taught that disease was not caused by the gods but by natural phenomena nor was its treatment to be found in prayer and sacrifice. Because his diagnostic armamentarium was necessarily limited to his five senses, he was much more interested in the course and treatment of disease than in its specific causes. He did subscribe to the widely accepted classical theory that disease was primarily due to an imbalance in the four humors (blood,

This paper was presented at the 49th Annual Meeting of the European Society of Pediatric Radiology, Athens, Greece, June 1, 2012.

B. R. Parker $(\bowtie)$

Stanford University and Lucile Salter Packard Children's Hospital, 725 Welch Rd., MC5913, Palo Alto, CA 94305, USA

e-mail: brparker@stanford.edu phlegm, yellow bile, black bile) and in their relationships to the four elements (earth, air, water, fire) that made up the natural world and also to naturally occurring celestial phenomena.

The substantial body of medical writings that has survived to the present time, known as the Hippocratic Corpus, comprises an unknown but probably small number of the genuine works of Hippocrates and numerous contributions by several generations of his disciples. Even the famed Hippocratic Oath is thought to have been composed no less than a century after Hippocrates himself flourished.

More to the point, however, is what possible relevance Hippocrates and the Hippocratic Corpus have to the practice of $21^{\text {st }}$-Century pediatric radiology. As noted above, Hippocrates showed little interest in diagnostics as we understand the concept but concentrated on course, therapy and prognosis. The theory and practice of Hippocratic medicine can be found today only in the ministrations of some practitioners of holistic and alternative medicine.

The corpus, however, contains the thoughts of the Hippocratic school on what we might call the philosophy and ethics of medicine and, indeed, pediatric radiology. Throughout the writings, Hippocrates showed great respect for the individual patient whose welfare was the means and end of Hippocratic practice. Perhaps of most importance is that Hippocrates established the earliest extant code of medical ethics.

Ethical teachings are found in several Hippocratic treatises, notably Epidemics I and the Hippocratic Oath. Within the corpus is the repeated admonition to do no harm to the patient. The ethical issues frequently dealt with fees charged by the physician, but issues of equality and patient privacy played a prominent role. Of particular note is that there is a responsibility to "treat slaves as one would the master," i.e. that all should be treated equally regardless of ability to pay. This latter concept may have been practiced more in the breach than in the observance in that it is likely that citizen-physicians treated citizens and slave-physicians treated slaves [4]. 
The most famous statements of medical ethics are found in the Hippocratic Oath. Likely written a century after Hippocrates practiced and taught, it is an oath sworn to the relevant deities. Prominent among its admonitions is to show respect for teachers and to acknowledge that all physicians have an obligation to teach. We are admonished to treat the sick, refrain from harm and injustice, and respect patient privacy among other responsibilities.

Why should pediatric radiologists concern themselves with medical ethics? What role does ethics play in our technologically oriented specialty? A joint commission of the American Board of Internal Medicine and the European Foundation for Internal Medicine declared that "Professional ethics is the basis of medicine's contract with society" [5]. If we substitute "radiology" for "medicine," we indeed have the answer.

Although not without debate [6], most medical ethicists subscribe to the following cardinal principles of medical ethics $[7,8]$ :

(1) Beneficence: The goal is to benefit the sick.

(2) Nonmaleficence: "Do no harm."

(3) Autonomy: The rights of patients.

(4) Justice: Treat the sick without regard for ability to pay.

Comparing Hippocratic principles with those of contemporary medical ethicists we find a remarkable correspondence (Table 1). But, more to the point, how do these general medical principles apply to pediatric radiologists?

\section{The principles of beneficence and nonmaleficence}

(1) Overview

- What is the patient's medical problem? Acute, chronic, critical, reversible, emergent, terminal?

- What are the goals of the imaging examination?

- When is the imaging examination not indicated?

- What is the probability of achieving a helpful result from the imaging examination?

- In sum, how can this patient benefit from an imaging examination and how can harm be avoided?

Table 1 The cardinal principles of medical ethics

\begin{tabular}{ll}
\hline Hippocrates & Contemporary \\
\hline - Obligation to teach & - Obligation to teach \\
- Benefit the sick & - Beneficence \\
- Refrain from harm and injustice & - Nonmaleficence-"Do no harm" \\
- Respect patience privacy & - Autonomy \\
- Treat slaves as one would treat & - Justice \\
the master & \\
\hline
\end{tabular}

(2) What is the patient's medical problem?

- Can we obtain relevant clinical information from the referring physician by personal communication or written order?

- Is the information available to us in the electronic medical record?

- Can we, or should we, ethically refuse an examination that we believe to be nonindicated, especially if potentially harmful, in the absence of appropriate clinical rationale?

(3) What are the goals of the imaging examination?

- Is the clinical question relevant to the patient's condition?

- Can the question be answered by the requested examination? Is there a different examination that can better answer the question?

- Will the result in any way affect the patient's treatment and/or prognosis?

(4) When is an imaging examination contraindicated?

- Is the requested examination appropriate to answer the clinical question?

- Will the imaging examination do more harm than good?

- Is the patient's prognosis such that the requested examination is irrelevant?

- What is the radiologist's responsibility in such cases?

\section{The principle of patient autonomy}

(1) Have indications, benefits and risks been explained? Have the risks of radiation, especially in children, been discussed?

(2) Have we explained the procedure in language the patient can understand? Have we eschewed medical jargon and attempted to discuss the examination in the patient's native tongue, if necessary, for complete understanding?

(3) When is formal informed consent required?

(4) Are we biasing the patient in favor of consent when we explain the procedure?

(5) How do we communicate the results? Do we deal directly with the patient or only through our report to the referring clinician?

(6) Do we approach the patient in a paternalistic mode or in partnership? 


\section{Justice}

(1) Justice is regarded as the equal distribution of health care among the population without regard to the ability to pay.

(2) Reduction in costs of imaging as a benefit to society.

(3) Evaluation of cost-effectiveness of imaging examinations.

An issue for physicians since the time of Hippocrates, and even before then in the Egyptian surgical papyri, has been the concept of doing no harm. Looking at pediatric radiology one can discern three cardinal sins that may harm the patient. Sins of omission generally are overlooking the pertinent imaging findings or diagnosis. The most common sin of commission is making an incorrect diagnosis or interpretation of the findings or performing a clearly nonindicated or contraindicated examination. All of us have been guilty of these sins of omission and commission, and there is no doubt that all of us strive to reduce these errors as much as possible in our own practices.

But, there is another sin to which we are heir and to which we give little attention: abdication of responsibility by the radiologist. Armstrong [9] has outlined the ethical responsibilities of the radiologist. It is likely that many of us abdicate one or more of these responsibilities, as slightly modified below, on a daily basis.

(1) Appropriateness of the imaging procedure.

(2) Informed consent, not just formal written consent but being sure that the patient truly understands the benefits and risks of the examination we are about to do.

(3) Patient protection has become a major topic in the past few years. It is a credit to our subspecialty that pediatric radiologists have been preaching radiation protection in children for decades.

(4) Image interpretation, the raison d'etre of our subspecialty.

(5) Communication with patients and referring clinicians.

(6) Continuous learning.

(7) Continuous quality improvement.

This list of ethical responsibilities is largely self-evident. However, the increased use of electronic technology has separated some of the processes from their traditional methods. As an example let us look at communication between clinicians and radiologists. For decades we relied largely on written communication via dictated, typed and mailed radiology reports. That delays in communication were likely was an accepted downside of the method. Most imaging departments have criteria for completion of reports, but how realistic are these? If a report is sent to the clinician 12-24 h after the patient has been seen, how much impact has the radiologist's interpretation had on patient care? Voice recognition software has been available for more than a decade, but even now there are radiologists who are opposed to its adoption even though the transmission time of results is markedly reduced. Do the perceived negatives of voice recognition outweigh the radiologist's responsibility to transmit results in the most efficacious manner?

PACS has now been almost universally accepted, but does it enhance or retard communication? How many of us bemoan the loss of daily conferences or face-to-face meetings with our clinical colleagues?

Have we forced ourselves to conform to the patterns of communication that are a result of the adoption of technological advances or can we still fulfill the radiologist's ethical responsibility to communicate accurately and rapidly?

Although the principles discussed in this paper are tailored to the pediatric radiologist, we must not forget that radiologists are, first and foremost, physicians. The welfare of the patient is the ultimate goal of our daily practices. The principles of beneficence, nonmaleficence, justice and patient autonomy apply to radiology as to all aspects of medical practice. But I propose that there is still one more principle unique to radiology: autonomy for the radiologist.

What freedom of practice should we demand if we are to fulfill all the other ethical principles to which we attempt to adhere? As examples, should we perform our procedures in the absence of pertinent clinical information and collegial consultation? Should we automatically perform any procedure requested of us? Should we communicate our findings directly to patients as their specialty physicians? Although most of us will answer these questions in the affirmative, don't we all see and excuse exceptions every day?

In an act of classical Greek hubris, I propose a modified Hippocratic Oath for pediatric radiologists:

- I swear by all in which I believe that I will apply my expertise, experience and judgment for the benefit of my patients.

- I will respect my professional forebears and endeavor to teach the next generation of radiologists all that I have learned for the benefit of their patients.

- I will respect the rights and privacy of my patients.

- I will refrain from doing harm to my patients.

- I will perform only those procedures that will benefit the patient and that will help the clinician devise an appropriate therapeutic plan.

- I will communicate my findings to the clinician expeditiously, accurately and collegially.

- If I respect this oath, may I gain the respect of my patients, my colleagues and my students.

Conflict of interest None.

\section{References}

1. Jones WHS (1923) Hippocrates I. Loeb classical library, vol 147. Harvard University Press, Cambridge, pp xxx11-xxx1v 
2. Jones WHS (1923) Hippocrates I. Loeb classical library, vol 147. Harvard University Press, Cambridge, p xl111

3. Juanna J (1999) Hippocrates (English translation: Bevoise MB). Johns Hopkins University Press, Baltimore, pp 3-24

4. Jonsen AR (2000) A short history of medical ethics. Oxford University Press, New York, pp 1-9

5. Brennan T, Blank L, Cohen J et al (2002) Physician charter. Ann Intern Med 136:243-246
6. Gunderman RB (2012) Ethics and the limits of principles. J Am Coll Radiol 9:225-226

7. Beauchamp TL, Childress JF (2009) Principles of biomedical ethics, 6th edn. Oxford University Press, New York, pp 12-13

8. Jonsen AR, Siegler M, Winslade WJ (2010) Clinical ethics, 7th edn. McGraw-Hill, New York, pp 2-5

9. Armstrong JD 2nd (1999) Morality, ethics and the radiologists' responsibilities. AJR Am J Roentgenol 173:279-284 